pp. $1-14$

\title{
PERILAKU PUNCHING SHEAR PADA HUBUNGAN KOLOM BULAT DENGAN FLAT SLAB AKIBAT BEBAN TEKAN AKSIAL
}

\author{
Muhammad Zardi ${ }^{1}$ \\ ${ }^{1)}$ Program Studi Teknik Sipil, Fakultas Teknik, Universitas Abulyatama \\ Jl. Blang Bintang Lama Km 8,5 Lampoh Keude Aceh Besar, \\ email: mr_zardi@yahoo.com
}

\begin{abstract}
The aim of the tests was to investigate the influence of concrete strength, the eccentricity of the column and the use of shear reinforcement in flat slabs on punching shear. The research specimens are 8 units of flat slabs. Flat slab size $1400 \times 1400 \mathrm{~mm} 2$ with thickness of $120 \mathrm{~mm}$. Flat slabs were connected with circular column with dimension $225 \mathrm{~mm}$ of diameter and $200 \mathrm{~mm}$ of height. Flat slabs were made in to 2 variations of concrete strength, e.i. $30 \mathrm{MPa}$ and $60 \mathrm{MPa}, 2$ variations of shear reinforcement, e.i. without shear reinforcement and with shear reinforcement and 2 variations of eccentricity that, e.i. without eccentricity and with eccentricity. Each treatment has 1 specimen. Each specimen has 6 cylinder specimens. Cylinder specimens used as a concrete strength control for main specimen (flat slab). The tests showed that the concrete strength had a strong influence on punching shear strength. This is shown by capacity increase of $42.78 \%$; $54.00 \%$; $46.59 \%$ and $0.02 \%$. The value is ratio between the maximum load of the specimens with $60 \mathrm{MPa}$ and $30 \mathrm{MPa}$ at the same eccentricity and the same shear reinforcement. The eccentricity of column reduce the capacity of punching shear. This is shown by 3 specimens decrease in capacity of 3.70\%; $36.75 \%$ and $7.30 \%$. Only 1 specimen that increase in capacity of $9.27 \%$. The value is ratio between the maximum load of the specimens with $40 \mathrm{~mm}$ eccentricity and $0 \mathrm{~mm}$ eccentricity at the same compressive strenght and the same shear reinforcement. The use of shear reinforcement does not always increase the punching shear capacity. There are 2 observations that increased capacity $(52.07 \%$ and $65.37 \%$ at the centric load) and 2 observations decreased capacity $(0.12 \%$ and $4.92 \%$ at the eccentric load). The value is ratio between the maximum load on the specimens using shear reinforcement with the specimens that do not use shear reinforcement at the same compressive strenght and the same eccentricity.The use of shear reinforcement increase punching shear capacity of flat slab at the centric load condition. The use of shear reinforcement decrease punching shear capacity of flat slab at the eccentric load condition.
\end{abstract}

Keywords : concrete strength, shear reinforcement, eccentricity, punching shear, flat slab, centric load, eccentric load.

\begin{abstract}
Abstrak: Penelitian ini bertujuan untuk mengetahui pengaruh mutu beton, eksentrisitas pada kolom dan penggunaan tulangan geser pada flat slab terhadap punching shear. Benda uji yang diteliti berupa flat slab sebanyak 8 buah. Flat slab berukuran $1400 \times 1400 \mathrm{~mm} 2$ dengan tebal $120 \mathrm{~mm}$. Flat slab dihubungkan dengan kolom bulat berdiameter penampang $225 \mathrm{~mm}$ dan tinggi $200 \mathrm{~mm}$. Flat slab dibuat dengan 2 variasi mutu beton yaitu $30 \mathrm{MPa}$ dan $60 \mathrm{MPa}$, 2 variasi tulangan geser yaitu tanpa tulangan geser dan pakai tulangan geser serta 2 variasi eksentrisitas yaitu tanpa eksentrisitas dan dengan eksentrisitas. Masing-masing benda uji berjumlah 1 buah untuk 1 perlakuan. Benda uji silinder dibuat sebanyak 6 buah untuk setiap benda uji flat slab. Benda uji silinder dipakai sebagai kontrol mutu beton untuk benda uji utama (flat slab). Hasil yang diperoleh dari penelitian adalah mutu beton berpengaruh terhadap kapasitas punching shear. Hal ini ditunjukkan dengan adanya peningkatan kapasitas sebesar $42,78 \%$; 54,00 \%; 46,59 \% dan 0,02\%. Nilai tersebut merupakan perbandingan antara beban maksimum pada benda uji $60 \mathrm{MPa}$ dengan benda uji $30 \mathrm{MPa}$ pada kondisi eksentrisitas dan penggunaan tulangan geser yang sama. Eksentrisitas kolom memperkecil kapasitas punching shear. Hal ini dilihat pada 3 pengamatan benda uji yang kapasitasnya turun masing-masing sebesar $3,70 \% ; 36,75 \%$ dan $7,30 \%$ sedangkan 1 pengamatan benda uji kapasitasnya naik sebesar $9,27 \%$. Nilai tersebut merupakan perbandingan antara beban
\end{abstract}


maksimum pada benda uji eksentrisitas 40 dengan benda uji eksentrisitas $0 \mathrm{~mm}$ pada kondisi mutu beton dan penggunaan tulangan geser yang sama. Penggunaan tulangan geser tidak selalu memperbesar kapasitas punching shear. Terdapat 2 pengamatan yang mengalami kenaikan kapasitas (sebesar 52,07 \% dan 6,46\% pada beban sentris) dan 2 pengamatan lagi mengalami penurunan kapasitas (sebesar $0,12 \%$ dan 4,92 \% pada beban eksentris). Nilai tersebut merupakan perbandingan antara beban maksimum pada benda uji yang menggunakan tulangan geser dengan benda uji yang tidak menggunakan tulangan geser pada kondisi mutu beton dan eksentrisitas yang sama. Penggunaan tulangan geser pada flat slab dapat memperbesar kapasitas punching shear pada kondisi beban sentris sedangkan penggunaan tulangan geser pada slab dengan kondisi beban eksentris justru memperkecil kapasitas punching shear.

Kata kunci : mutu beton, tulangan geser, eksentrisitas, punching shear, flat slab, beban sentris, beban eksentris.

Pesatnya perkembangan populasi masyarakat, keterbatasan lahan yang ada serta kebutuhan akan bangunan bertingkat banyak yang meningkat menuntut diadakannya pembangunan secara vertikal. Oleh karena itu inovasi rekayasa teknik sipil sangat diperlukan. Salah satu perwujudan hal tersebut adalah pemanfaatan sistem struktur flat sla $b$ untuk bangunan gedung bertingkat.

Struktur flat slab adalah struktur bangunan dimana lantainya ditumpu langsung di atas kolom tanpa adanya balok. Penggunaan struktur flat slab sebagai sistem struktur di negara-negara maju sudah berkembang pesat. Di tanah air seperti di Jakarta, pembangunan struktur bangunan tinggi juga sudah mulai menggunakan sistem sebagai alternatif yang baik.

Punching shear merupakan gaya geser dua arah yang bekerja pada slab yang menyebabkan slab mengalami desak setempat. Beberapa riset yang ada telah menjelaskan mengenai fenomena punching shear pada struktur flat slab.

Kehancuran akibat punching shear ini dapat terjadi dengan tiba-tiba tanpa ada peringatan awal. Oleh karena itu fenomena punching shear menarik untuk diteliti dengan harapan dapat menemukan solusi agar kehancuran yang tiba-tiba bisa dicegah.

Penelitian ini berkonsentrasi pada punching shear yang terjadi pada flat slab. Fenomena yang ingin dilihat adalah pengaruh mutu beton, eksentrisitas pada pembebanan kolom dan penggunaan tulangan geser pada flat slab terhadap punching shear.

\section{KAJIAN PUSTAKA}

Fenomena yang paling umum terjadi pada hubungan slab-kolom adalah punching shear.

\section{Kapasitas Beban Aksial Kolom}

Kolom merupakan elemen struktur yang lazim direncanakan untuk menahan beban tekan. Kapasitas beban tekan aksial kolom yang dikutip dari MacGregor (1997) seperti terlihat pada persamaan di bawah ini.

$\mathrm{P}_{0}=0,85 \mathrm{f}^{\prime}{ }_{\mathrm{c}}\left(\mathrm{A}_{\mathrm{g}}-\mathrm{A}_{\mathrm{st}}\right)+\mathrm{f}_{\mathrm{y}} \times \mathrm{A}_{\mathrm{st}}$

dimana:

$\mathrm{P}_{0}=$ kapasitas $\operatorname{kolom}(\mathrm{N})$;

$\mathrm{A}_{\mathrm{g}}=$ luas bruto penampang beton $\left(\mathrm{mm}^{2}\right)$;

$\mathrm{A}_{\mathrm{st}}=$ luas penampang tulangan pokok $\left(\mathrm{mm}^{2}\right)$;

$\mathrm{f}^{\prime} \mathrm{c}=$ mutu beton $(\mathrm{MPa})$; dan

$\mathrm{f}_{\mathrm{y}}=$ mutu baja tulangan pokok (MPa). 
Kekuatan kolom dalam memikul beban didasarkan pada kemampuannya memikul kombinasi beban aksial $(\mathrm{Pu})$ dan momen $\mathrm{Mu}$ ) secara bersamaan. Perencanaan kolom suatu struktur bangunan didasarkan pada kekuatan dan kekakuan penampang lintangnya terhadap aksi beban aksial dan momen lentur.

\section{Pengaruh Mutu Beton terhadap}

\section{Punching Shear}

Mutu beton diyakini mempunyai pengaruh besar terhadap punching shear. Penelitian yang dilakukan oleh Hallgren, Kinnunen dan Nylender (2002) menunjukkan bahwa mutu beton mempunyai pengaruh yang sangat besar terhadap kemampuan beton untuk menahan punching shear. Hasil penelitian yang dilakukan dapat dilihat pada Gambar 1.

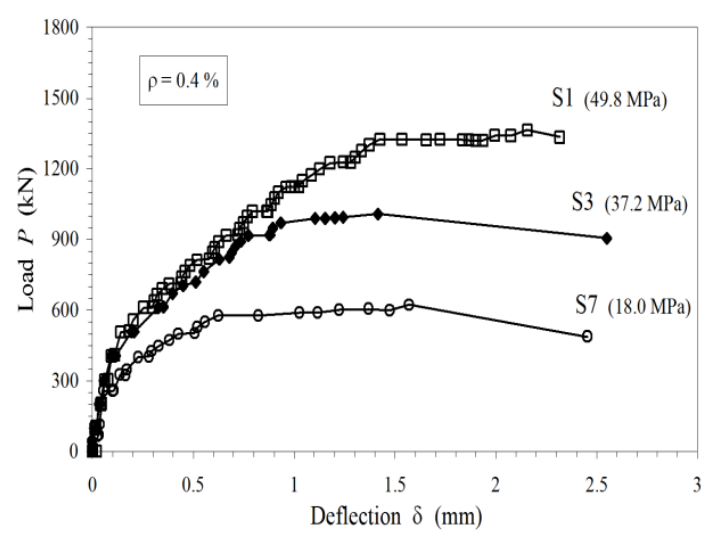

Gambar 1. Grafik hubungan bebandefleksi slab untuk berbagai mutu beton

Sumber: Hallgren, Kinnunen dan Nylander 2002

Tegangan geser izin beton untuk plat berdasarkan SNI 03-2847-2002 harus diambil sebagai nilai terkecil dari persamaan 2, 3 dan 4.

Volume 1, No. 1, Januari 2015
$V_{c}=\left(1+\frac{2}{\beta_{c}}\right) \frac{\sqrt{f_{c}^{\prime}} b_{o} d}{6}$

$V_{c}=\left(\frac{a_{s} d}{b_{o}}+2\right) \frac{\sqrt{f_{c}^{\prime}} b_{o} d}{12}$

$V_{c}=\frac{1}{3} \sqrt{f_{c}^{\prime}} b_{o} d$

dimana :

$\mathrm{V}_{\mathrm{c}}=$ kuat geser nominal yang disumbangkan oleh beton $(\mathrm{N})$;

$\beta_{\mathrm{c}}=$ rasio dari sisi panjang terhadap sisi pendek pada kolom, daerah beban terpusat atau daerah reaksi;

$\alpha_{\mathrm{s}}=40$ untuk kolom dalam, 30 untuk kolom tepi, 20 untuk kolom sudut;

$\mathrm{f}^{\prime}{ }_{\mathrm{c}}=$ kuat tekan beton (MPa);

$\mathrm{b}_{0}=$ keliling dari penampang kritis pada plat (mm); dan

$\mathrm{d}=$ adalah jarak dari serat tekan terluar ke titik berat tulangan tarik longitudinal $(\mathrm{mm})$.

\section{Pengaruh Tulangan Geser Terhadap}

\section{Punching Shear}

Tulangan geser mempunyai andil yang tidak bisa diabaikan terhadap punching shear. Beberapa penelitian menunjukkan pengaruh tulangan geser yang sangat besar di mana kapasitas geser beton naik secara signifikan seperti dapat dilihat pada Gambar 2.

Peraturan mengenai tahanan geser beton dan tulangan geser sangat bervariasi. Ada peraturan yang menambahkan nilai-nilai tertentu, ada juga yang mengurangi luas beton atau efisiensi dari tulangan geser. Beberapa peraturan memperluas tulangan geser sampai pada suatu batas tertentu. Akibatnya adalah tulangan geser dan daerah yang membutuhkan tulangan geser menjadi bertambah (Albrecht, 2002). 


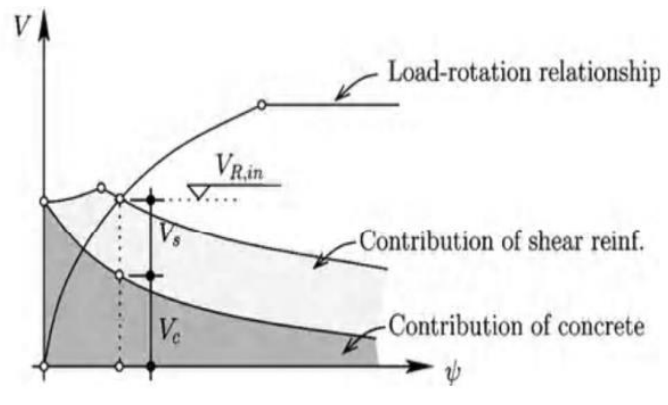

Gambar 2. Grafik hubungan rotasiSumber: Ruiz dan Muttoni 2009

Selain menaikkan kapasitas geser beton, penggunaan tulangan geser juga memperbesar bidang kritis plat. Dengan demikian kehancuran plat tidak dimulai dari pinggir kolom, melainkan dari pinggir tulangan geser ke arah luar kolom (Gambar 3).
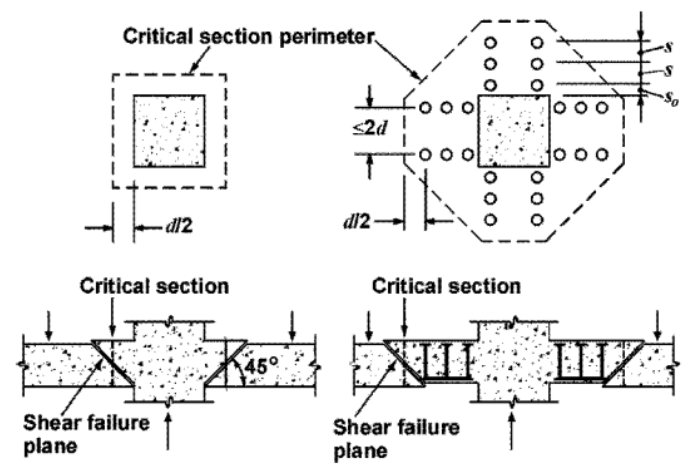

Gambar 3. Bidang kritis untuk slab yang memakai dan yang tidak memakai tulangan geser

Sumber: Ruiz dan Muttoni 2009

\section{Pengaruh Eksentrisitas terhadap \\ Punching Shear}

Hasil penelitian yang dilakukan Krüger, Burdet dan Favre (1998) menunjukkan bahwa momen pada kolom dapat menyebabkan berkurangnya kapasitas punching shear pada flat slab. Gambar 4 menunjukkan adanya perbedaan kapasitas beban yang nyata antara benda uji sentris dan benda uji eksentris.

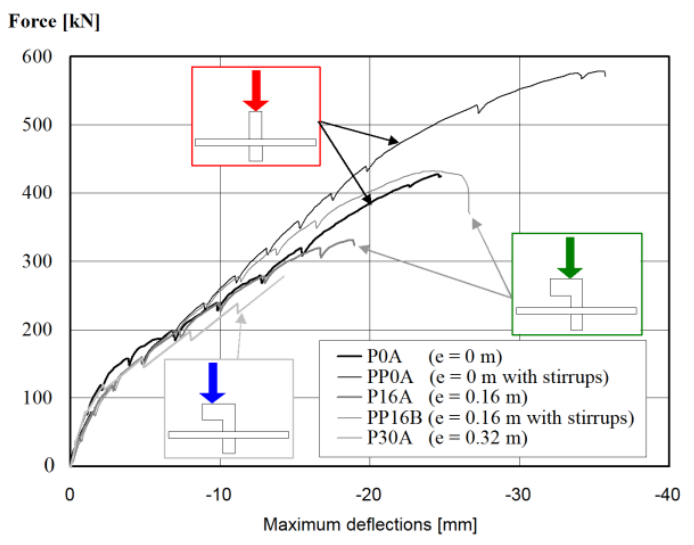

Gambar 4. Grafik hubungan bebandefleksi untuk benda uji sentris dan benda uji eksentris

Sumber : Krüger, Burdet dan Favre 1998

\section{METODE PENELITIAN}

Benda uji yang digunakan dalam penelitian ini adalah flat slab yang dibuat dalam 2 variasi mutu beton, 2 variasi tulangan geser dan 2 variasi eksentrisitas. Masing-masing benda uji diberi nomor agar tidak tertukar antara benda uji yang satu dengan benda uji yang lain. Setiap pengecoran benda uji juga dilakukan pembuatan benda uji silinder untuk mengontrol mutu beton. Untuk lebih jelasnya penomoran benda uji yang dibuat disajikan pada Tabel 1.

Tabel 1. Penomoran benda uji

\begin{tabular}{|c|c|c|c|}
\hline $\begin{array}{c}\text { Tulangan } \\
\text { geser }\end{array}$ & $\begin{array}{c}\text { Mutu } \\
\text { beton }\end{array}$ & \multicolumn{2}{|c|}{ Eksentrisitas } \\
\cline { 3 - 4 } $\begin{array}{c}\text { Tanpa } \\
\text { tulangan } \\
\text { geser }\end{array}$ & $30 \mathrm{MPa}$ & $\mathrm{FC}_{30} \mathrm{E}_{0} \mathrm{SR}_{0}$ & $\mathrm{FC}_{30} \mathrm{E}_{40} \mathrm{SR}_{0}$ \\
\cline { 2 - 4 } & $60 \mathrm{MPa}$ & $\mathrm{FC}_{60} \mathrm{E}_{0} \mathrm{SR}_{0}$ & $\mathrm{FC}_{60} \mathrm{E}_{40} \mathrm{SR}_{0}$ \\
\hline \multirow{2}{*}{$\begin{array}{c}\text { Pakai } \\
\text { tulangan } \\
\text { geser }\end{array}$} & $30 \mathrm{MPa}$ & $\mathrm{FC}_{30} \mathrm{E}_{0} \mathrm{SR}_{1}$ & $\mathrm{FC}_{30} \mathrm{E}_{40} \mathrm{SR}_{1}$ \\
\cline { 2 - 4 } & $60 \mathrm{MPa}$ & $\mathrm{FC}_{60} \mathrm{E}_{0} \mathrm{SR}_{1}$ & $\mathrm{FC}_{60} \mathrm{E}_{40} \mathrm{SR}_{1}$ \\
\hline
\end{tabular}


Benda uji dibuat berdasarkan SNI 032847-2002 tentang Tata Cara Perhitungan Struktur Beton untuk Bangunan Gedung, ASTM C 33-93 tentang Standar Spesifikasi Agregat Beton, SNI 03-2493-1991 tentang Metode Pembuatan dan Perawatan Benda Uji Beton di Laboratorium, SNI 03-1974-1990 tentang Metode Pengujian Kuat Tekan Beton, SNI 07-2529-1991 tentang Metode Pengujian Kuat Tarik Baja Beton dan ACI 211.1-91 tentang Perencanaan Campuran Beton Normal.

\section{Deskripsi Benda Uji}

Benda uji merupakan beton bertulang yang berukuran $1400 \times 1400 \mathrm{~mm}^{2}$ dengan tebal $120 \mathrm{~mm}$. Flat slab dihubungkan dengan kolom bulat dengan diameter penampang 225 $\mathrm{mm}$ dan tinggi $200 \mathrm{~mm}$. Untuk lebih jelasnya bentuk detail benda uji Gambar 5 .

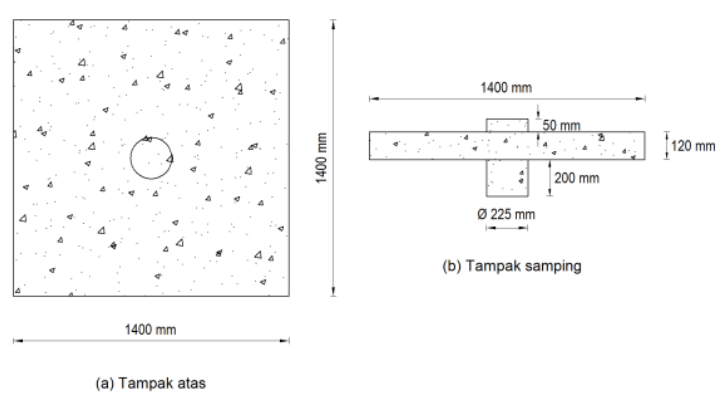

\section{Gambar 5. Benda uji flat slab}

\section{Pembuatan dan Perawatan Benda Uji}

Pembuatan benda uji dikerjakan sesuai dengan detil benda uji (Gambar 6 dan Gambar 7). Flat slab diberi tulangan agar tidak terjadi kegagalan lentur. Kolom juga diberi tulangan agar sanggup menahan beban yang diberikan.

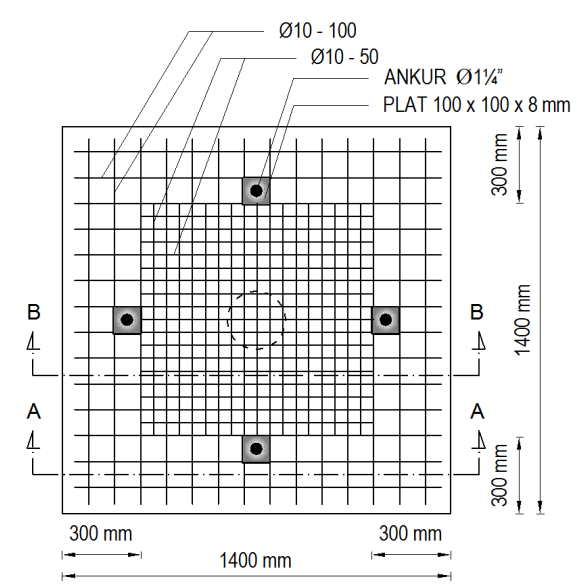

(a) Pembesian flat slab

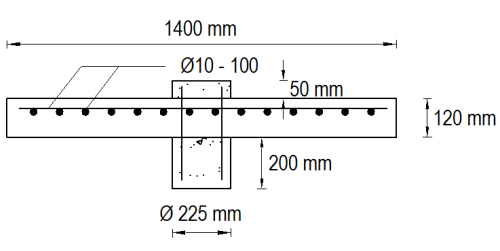

(b) Potongan A - A

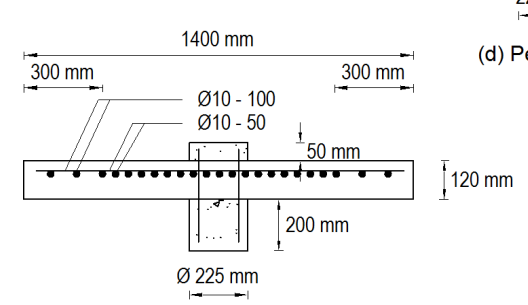

(c) Potongan B - B

Gambar 6. Detil benda uji flat slab dengan mutu f'c $30 \mathrm{MPa}$

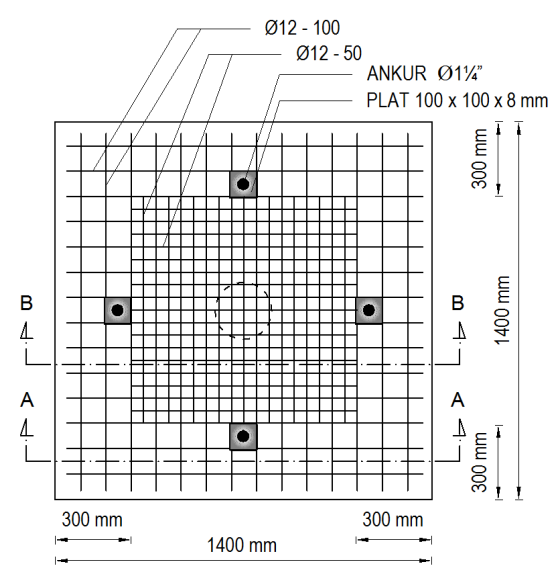

(a) Pembesian flat slab

Gambar 7a. Detil benda uji flat slab dengan mutu f'c $60 \mathrm{MPa}$ 


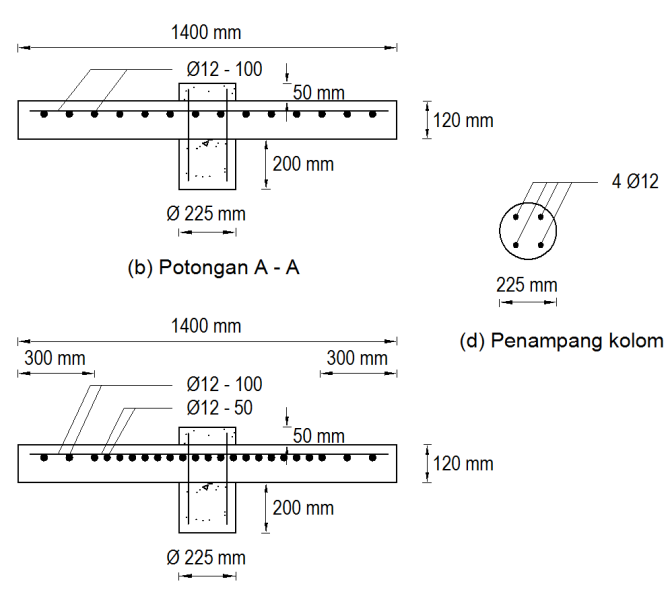

(c) Potongan B - B

Gambar $7 b$. Detil benda uji flat slab dengan mutu f'c 60 MPa

Mutu baja tulangan yang digunakan yaitu fy $320 \mathrm{MPa}$. Flat slab dianker ke lantai (strong floor) dengan posisi kolom berada di bawah. Rangkaian benda uji dapat dilihat pada Gambar 8 dan Gambar 9.

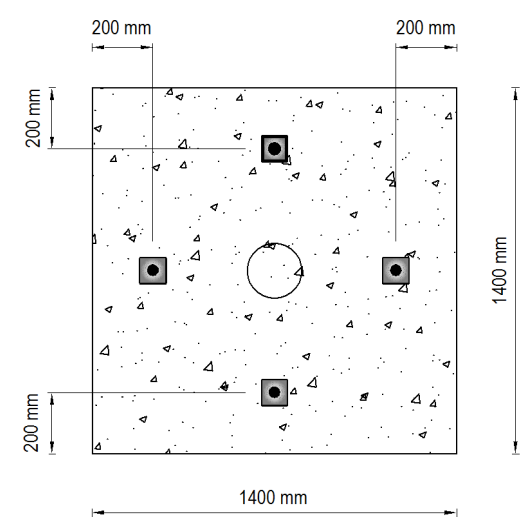

(a) Tampak atas

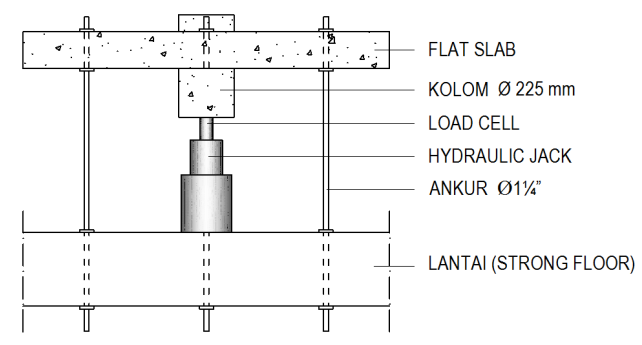

(b) Tampak samping

\section{Gambar 8. Rangkaian benda uji}

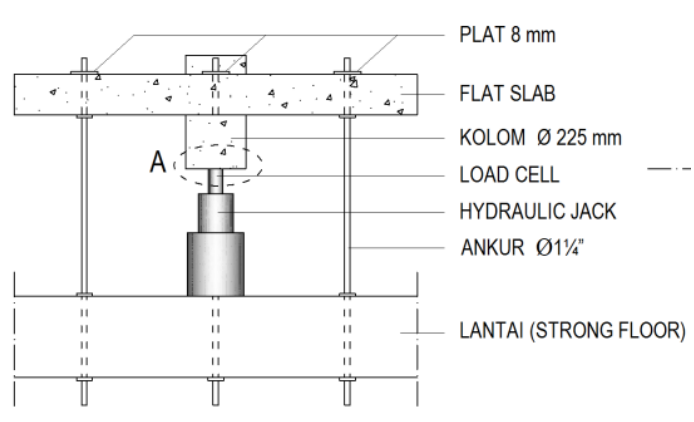

(a) Rangkaian benda uji

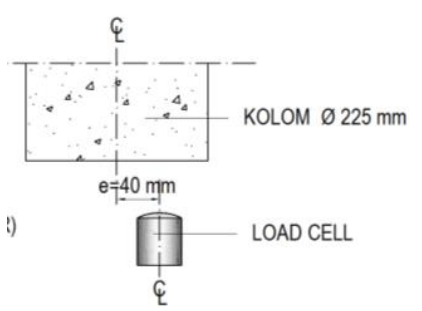

(b) Detil A

\section{Gambar 9. Rangkaian benda uji dengan eksentrisitas}

Untuk benda uji yang memakai tulangan geser, sudut tulangan geser $(\alpha)$ dipasang $90^{\circ}$ atau tegak lurus bidang slab. Tulangan geser yang digunakan berupa sengkang diameter 8 $\mathrm{mm}$ berbentuk segiempat dan dipasang sampai sejauh $90 \mathrm{~mm}$ (d) dari sisi kolom dengan jarak $50 \mathrm{~mm}$. Untuk memudahkan pemasangan tulangan geser, pada sisi bawah slab dipasang tulangan dengan diameter 10 mm. Rangkaian benda uji dengan tulangan geser dapat dilihat pada Gambar 10. 


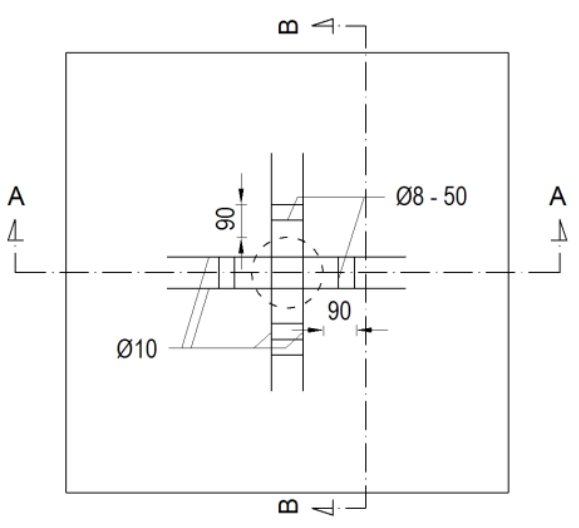

(a) Penempatan tulangan geser

Gambar 10a. Penempatan tulangan geser

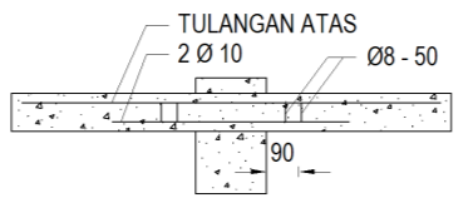

(b) Potongan A - A

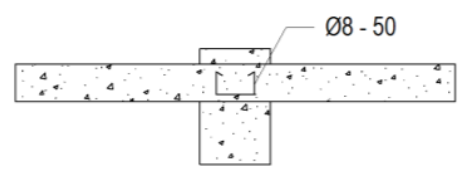

(c) Potongan B - B

\section{Gambar 10b. Penempatan tulangan geser}

\section{Prosedur Pengetesan Benda Uji}

Pengetesan benda uji dilakukan saat umur benda uji 28 hari atau ketika beton sudah mencapai mutu yang diinginkan. Benda uji flat slab dianker ke lantai dengan

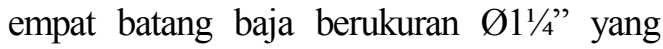
dipasang membentuk segi empat dengan jarak $200 \mathrm{~mm}$ dari pinggir slab.

Pembacaan data dari pengujian dimonitor dan direkam dengan menggunakan Portable Data Logger TDS-302. Penelitian ini menggunakan 11 nomor seri yang disambungkan dengan kabel-kabel listrik yaitu pada 5 buah pada transduser dan 6 buah pada strain gage.

Data lendutan diperoleh dengan memasang 5 buah transduser tipe CDP-100 dengan ketelitian $100 \times 10^{-6}$. Regangan yang terjadi pada beton dan tulangan dimonitor dengan memasang strain gage. Data regangan diperoleh dari alat ukur electric gages tipe KFG-10-120-CL-11 untuk baja tulangan yang dipasang sebelum pengecoran dan tipe PL-60 untuk beton yang dipasang sebelum pengujian.

Strain gage pada flat slab dipasang pada beton dan tulangan pada arah memanjang dan melintang slab. Sedangkan strain gage pada kolom dipasang pada daerah tekan beton dan daerah tarik tulangan. Cara pemasangan strain gage beton sama dengan pemasangan strain gage baja.

Titik penempatan transduser dan posisi strain gage beton dapat dilihat pada Gambar 11 dan Gambar 12. Sebelum pengujian dimulai, kabel-kabel penghubung harus dipastikan berfungsi dengan baik serta data logger telah diprogram.

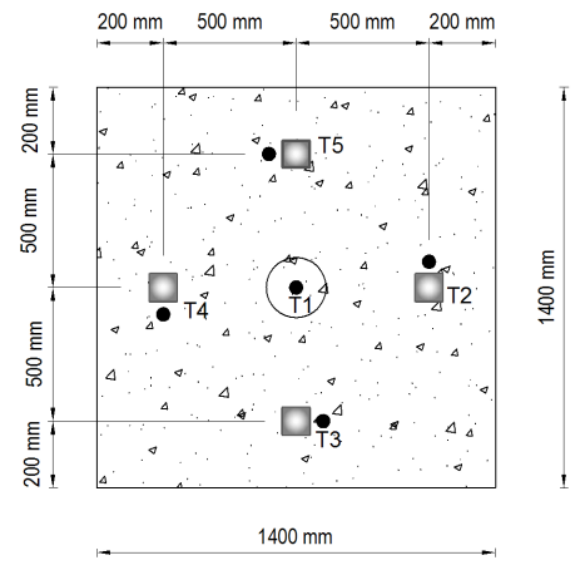

(a) Tampak atas 


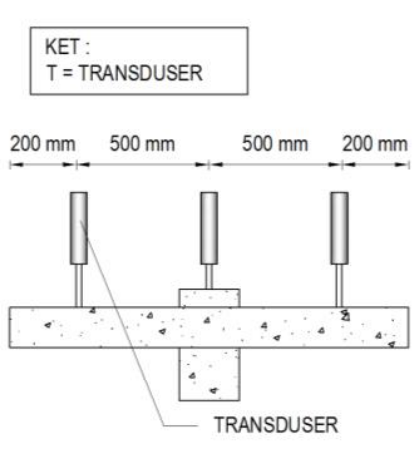

(b) Tampak samping

\section{Gambar 11. Penempatan transduser}

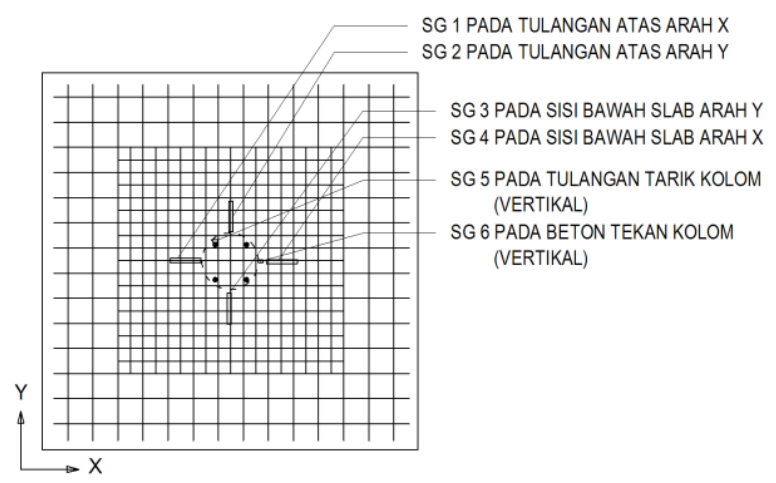

(a) Tampak atas

KET : $S G=S T R A I N G A G E$

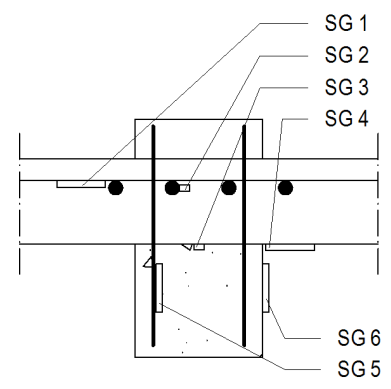

(b) Tampak samping

\section{Gambar 11. Penempatan strain gage}

\section{Campuran Beton}

Mix design untuk beton f'c $30 \mathrm{MPa}$ dibuat berdasarkan ACI 211.1-91. Jumlah air untuk campuran beton didasarkan pada tinggi slump rencana yaitu $75-100 \mathrm{~mm}$ dengan diameter agregat maksimum 25,4 mm. Faktor
Air Semen (FAS) direncanakan sebesar 0,54. Agregat kasar yang digunakan berupa kerikil dan tidak menggunakan additive.

Mix design untuk beton f'c $60 \mathrm{MPa}$ dibuat berdasarkan metode trial error dengan mengacu kepada total volume campuran beton yang dihasilkan sebesar 1000 liter. Untuk beton f'c $60 \mathrm{MPa}$, agregat kasar yang digunakan berupa batu pecah serta additive berupa super plasticizer sebanyak $2 \%$ dan silica fume sebanyak $8 \%$ dari berat semen. Produk yang digunakan adalah Sikament NN dan Sikafume yang diproduksi oleh PT. Sika Indonesia.

\section{HASIL DAN PEMBAHASAN}

\section{Benda Uji $\mathrm{FC}_{30} \mathrm{E}_{0} \mathrm{SR}_{0}$}

$\mathrm{FC}_{30} \mathrm{E}_{0} \mathrm{SR}_{0}$ merupakan benda uji dengan mutu beton f'c $30 \mathrm{MPa}$, eksentrisitas $0 \mathrm{~mm}$ (beban sentris) dan tanpa tulangan geser. Data hasil penelitian dapat dilihat pada Gambar 12.

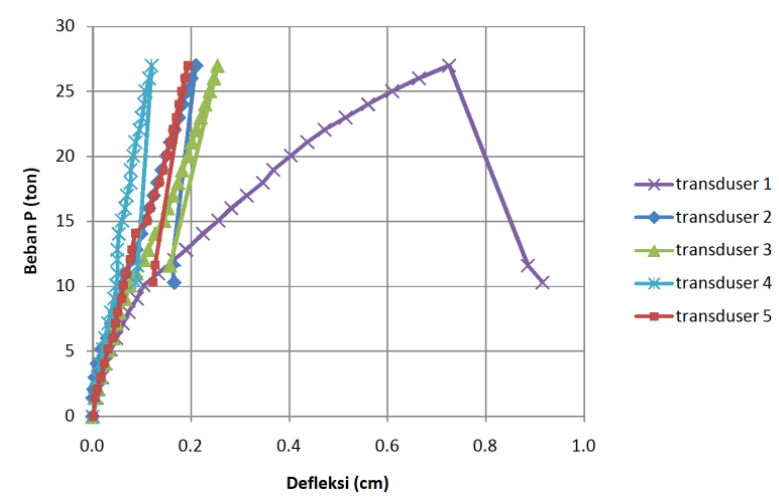

Gambar 12. Grafik beban-defleksi benda uji $\mathrm{FC}_{30} \mathrm{E}_{0} \mathrm{SR}_{0}$

Beban maksimum yang dihasilkan sebesar 27,00 ton dengan retak awal terjadi pada 11,10 ton. 


\section{Benda Uji $\mathrm{FC}_{30} \mathrm{E}_{40} \mathrm{SR}_{0}$}

$\mathrm{FC}_{30} \mathrm{E}_{40} \mathrm{SR}_{0}$ merupakan benda uji dengan mutu beton f'c $30 \mathrm{MPa}$, eksentrisitas $40 \mathrm{~mm}$ dan tanpa tulangan geser. Data hasil penelitian dapat dilihat pada Gambar 13.

Beban maksimum yang dihasilkan sebesar 26,00 ton dengan retak awal terjadi pada 12,60 ton.
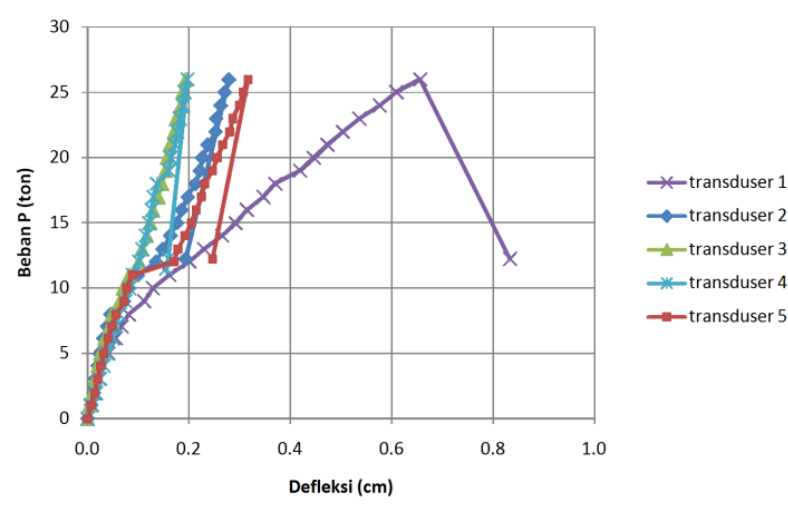

Gambar 13. Grafik beban-defleksi benda uji $\mathrm{FC}_{30} \mathbf{E}_{40} \mathrm{SR}_{0}$

\section{Benda Uji $\mathrm{FC}_{30} \mathrm{E}_{0} \mathrm{SR}_{1}$}

$\mathrm{FC}_{30} \mathrm{E}_{0} \mathrm{SR}_{1}$ merupakan benda uji dengan mutu beton f'c $30 \mathrm{MPa}$, eksentrisitas $0 \mathrm{~mm}$ (beban sentris) dan memakai tulangan geser. Data hasil penelitian dapat dilihat pada Gambar 14.

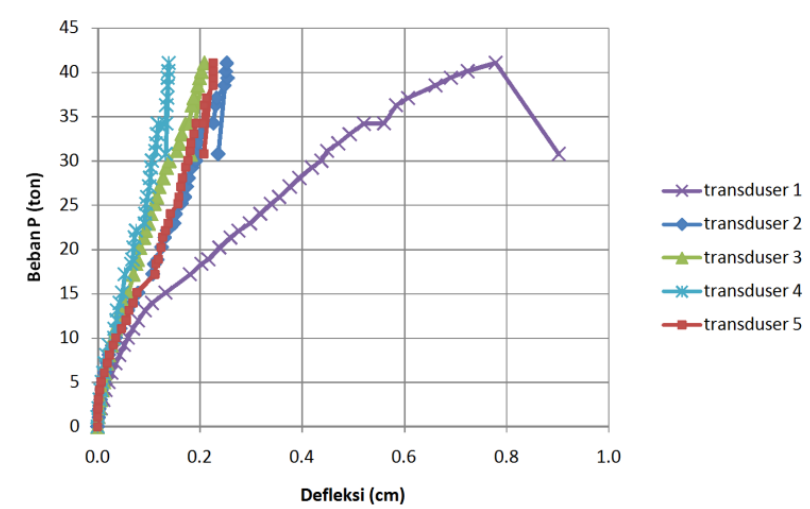

\section{Gambar 14. Grafik beban-defleksi benda uji $\mathrm{FC}_{30} \mathrm{E}_{0} \mathrm{SR}_{1}$}

Beban maksimum yang dihasilkan sebesar 41,06 ton dengan retak awal terjadi pada 16,07 ton.

\section{Benda Uji $\mathrm{FC}_{30} \mathbf{E}_{40} \mathrm{SR}_{1}$}

$\mathrm{FC}_{30} \mathrm{E}_{40} \mathrm{SR}_{1}$ merupakan benda uji dengan mutu beton f'c $30 \mathrm{MPa}$, eksentrisitas $40 \mathrm{~mm}$ dan memakai tulangan geser. Data hasil penelitian dapat dilihat pada Gambar 15.

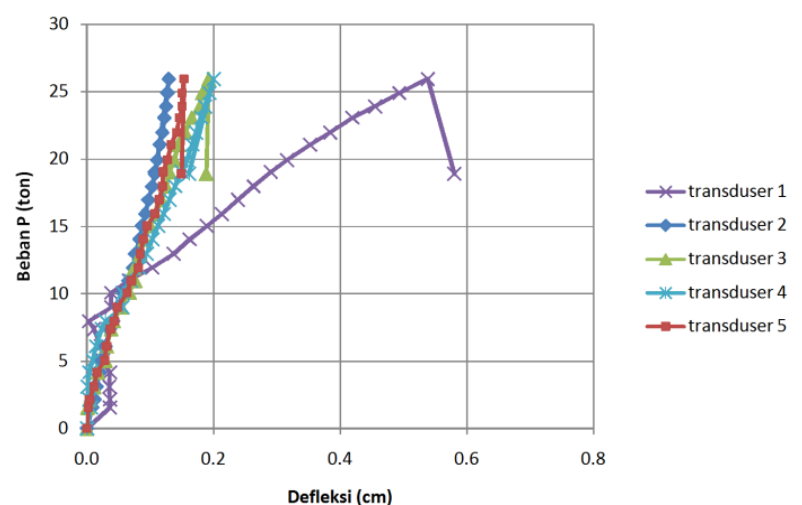

\section{Gambar 15. Grafik beban-defleksi benda uji $\mathrm{FC}_{30} \mathrm{E}_{40} \mathrm{SR}_{1}$}

Beban maksimum yang dihasilkan sebesar 25,97 ton dengan retak awal terjadi pada 14,50 ton.

\section{Benda Uji $\mathrm{FC}_{60} \mathrm{E}_{0} \mathrm{SR}_{0}$}

$\mathrm{FC}_{60} \mathrm{E}_{0} \mathrm{SR}_{0}$ merupakan benda uji dengan mutu beton f'c $60 \mathrm{MPa}$, eksentrisitas $0 \mathrm{~mm}$ (beban sentris) dan tanpa tulangan geser. Data hasil penelitian dapat dilihat pada Gambar 16. 


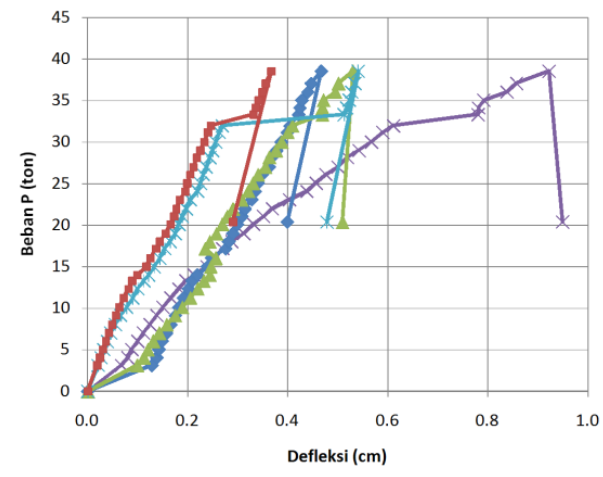

Gambar 16. Grafik beban-defleksi benda uji $\mathrm{FC}_{60} \mathrm{E}_{0} \mathrm{SR}_{\mathbf{0}}$

Beban maksimum yang dihasilkan sebesar 38,55 ton dengan retak awal terjadi pada 15,00 ton.

\section{Benda Uji $\mathrm{FC}_{60} \mathrm{E}_{40} \mathrm{SR}_{\mathbf{0}}$}

$\mathrm{FC}_{60} \mathrm{E}_{40} \mathrm{SR}_{0}$ merupakan benda uji dengan mutu beton f'c $60 \mathrm{MPa}$, eksentrisitas $40 \mathrm{~mm}$ dan tanpa tulangan geser. Data hasil penelitian dapat dilihat pada Gambar 17.

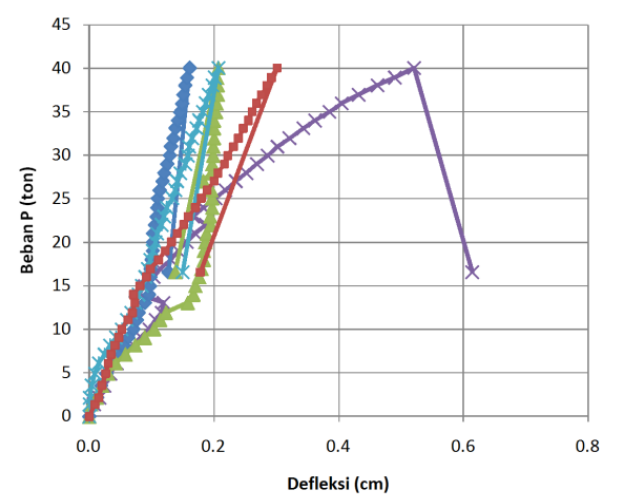

$*$ transduser $\leadsto$ transduser 2 - - transduser 3 - transduser 5

Gambar 17. Grafik beban-defleksi benda uji $\mathrm{FC}_{60} \mathrm{E}_{40} \mathrm{SR}_{0}$

Beban maksimum yang dihasilkan sebesar 40,04 ton dengan retak awal terjadi pada 12,00 ton.

\section{Benda $\mathrm{Uji}_{\mathrm{FC}} \mathrm{F}_{0} \mathrm{E}_{0} \mathrm{SR}_{1}$}

$\mathrm{FC}_{60} \mathrm{E}_{0} \mathrm{SR}_{1}$ merupakan benda uji dengan mutu beton f'c $60 \mathrm{MPa}$, eksentrisitas $0 \mathrm{~mm}$ (beban sentris) dan memakai tulangan geser. Data hasil penelitian dapat dilihat pada Gambar 18.

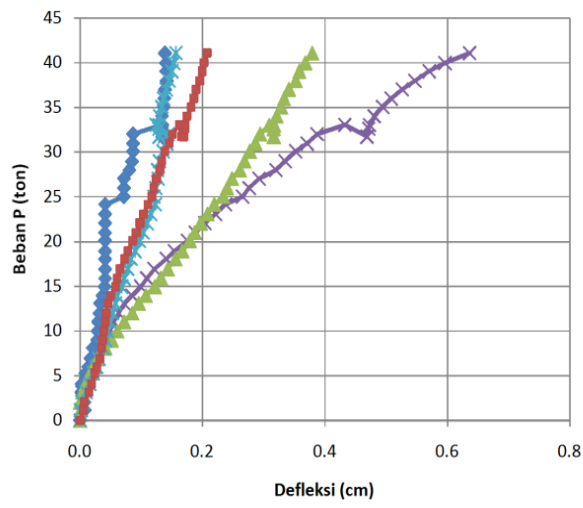

Gambar 18. Grafik beban-defleksi benda uji $\mathrm{FC}_{60} \mathrm{E}_{0} \mathrm{SR}_{1}$

Beban maksimum yang dihasilkan sebesar 41,07 ton dengan retak awal terjadi pada 11,50 ton.

\section{Benda Uji $\mathrm{FC}_{60} \mathrm{E}_{40} \mathrm{SR}_{1}$}

$\mathrm{FC}_{60} \mathrm{E}_{40} \mathrm{SR}_{1}$ merupakan benda uji dengan mutu beton f'c $60 \mathrm{MPa}$, eksentrisitas $40 \mathrm{~mm}$ dan memakai tulangan geser. Data hasil penelitian dapat dilihat pada Gambar 19.

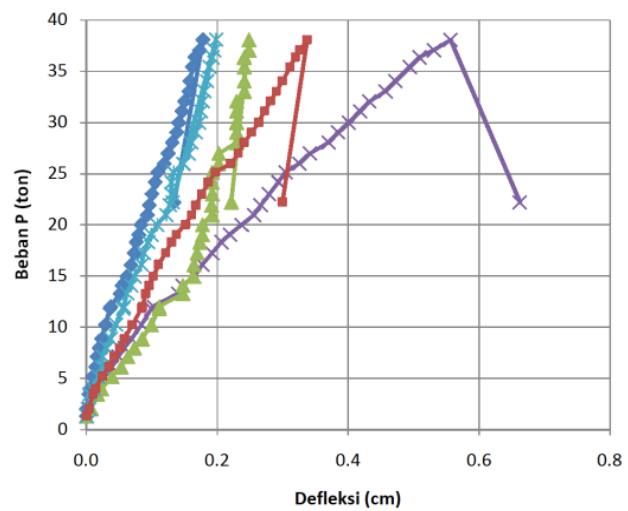

Gambar 19. Grafik beban-defleksi benda uji $\mathrm{FC}_{60} \mathrm{E}_{40} \mathrm{SR}_{1}$

Beban maksimum yang dihasilkan sebesar 38,07 ton dengan retak awal terjadi 
pada 12,50 ton.

\section{Pengaruh Mutu Beton}

Beban maksimum yang terjadi pada benda uji dengan mutu f'c $30 \mathrm{MPa}$ dan f'c 60 MPa dapat dilihat pada Gambar 20.

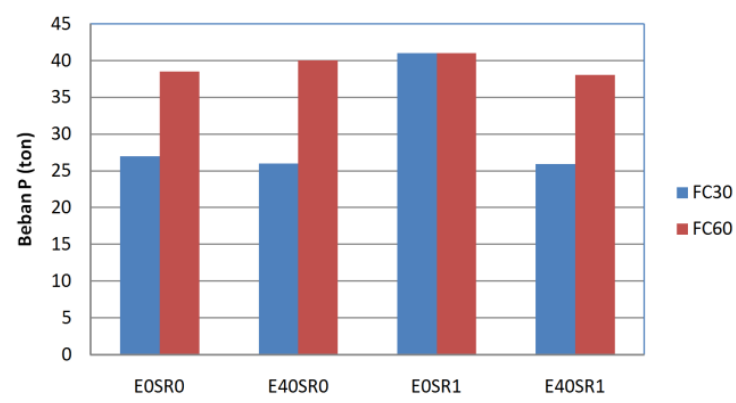

Gambar 20. Grafik kapasitas punching shear benda uji 30 MPa dan 60 MPa pada berbagai kondisi

Beban maksimum $\mathrm{FC}_{30} \mathrm{E}_{0} \mathrm{SR}_{0}$ sebesar 27,00 ton, sedangkan beban maksimum $\mathrm{FC}_{60} \mathrm{E}_{0} \mathrm{SR}_{0}$ lebih besar yaitu sebesar 38,55 ton (terjadi peningkatan sebesar 42,78 \%). Beban maksimum $\mathrm{FC}_{30} \mathrm{E}_{40} \mathrm{SR}_{0}$ sebesar 26,00 ton, sedangkan beban maksimum $\mathrm{FC}_{60} \mathrm{E}_{40} \mathrm{SR}_{0}$ lebih besar yaitu sebesar 40,04 ton (terjadi peningkatan sebesar 54,00 \%). Beban maksimum $\mathrm{FC}_{30} \mathrm{E}_{40} \mathrm{SR}_{1}$ sebesar 25,97 ton, sedangkan beban maksimum $\mathrm{FC}_{60} \mathrm{E}_{40} \mathrm{SR}_{1}$ lebih besar yaitu sebesar 38,07 ton (terjadi peningkatan sebesar 46,59 \%). Beban maksimum $\mathrm{FC}_{30} \mathrm{E}_{0} \mathrm{SR}_{1}$ dan $\mathrm{FC}_{60} \mathrm{E}_{0} \mathrm{SR}_{1}$ hampir sama yaitu 41,06 ton dan 41,07 ton (terjadi peningkatan sebesar 0,02\%). Data di atas menunjukkan bahwa mutu beton berpengaruh terhadap kapasitas punching shear dimana terdapat peningkatan beban maksimum pada mutu beton yang lebih besar.

\section{Pengaruh Eksentrisitas Pada Kolom}

Beban maksimum $\mathrm{FC}_{30} \mathrm{E}_{0} \mathrm{SR}_{0}$ sebesar 27,00 ton, sedangkan beban maksimum $\mathrm{FC}_{30} \mathrm{E}_{40} \mathrm{SR}_{0}$ lebih kecil yaitu sebesar 26,00 ton (terjadi penurunan sebesar 3,70\%). Beban maksimum $\mathrm{FC}_{30} \mathrm{E}_{0} \mathrm{SR}_{1}$ sebesar 41,06 ton, sedangkan beban maksimum $\mathrm{FC}_{30} \mathrm{E}_{40} \mathrm{SR}_{1}$ lebih kecil yaitu sebesar 25,97 ton (terjadi penurunan sebesar 36,75 \%). Beban maksimum $\mathrm{FC}_{60} \mathrm{E}_{0} \mathrm{SR}_{0}$ sebesar 38,55 ton, sedangkan beban maksimum $\mathrm{FC}_{60} \mathrm{E}_{40} \mathrm{SR}_{0}$ lebih besar yaitu sebesar 40,04 ton (terjadi peningkatan sebesar 3,87 \%). Beban maksimum $\mathrm{FC}_{60} \mathrm{E}_{0} \mathrm{SR}_{1}$ sebesar 41,07 ton sedangkan beban maksimum $\mathrm{FC}_{60} \mathrm{E}_{40} \mathrm{SR}_{1}$ lebih kecil yaitu sebesar 38,07 ton (terjadi penurunan sebesar $7,30 \%$ ). Data di atas dapat dilihat pada Gambar 21.

Data pada grafik tersebut menunjukkan ada 3 pengamatan benda uji yang beban maksimumnya lebih besar pada beban sentris. Sedangkan 1 pengamatan benda uji lagi menunjukkan beban maksimumnya lebih besar pada beban eksentris. Dengan demikian beban maksimum yang terjadi lebih besar pada beban sentris.

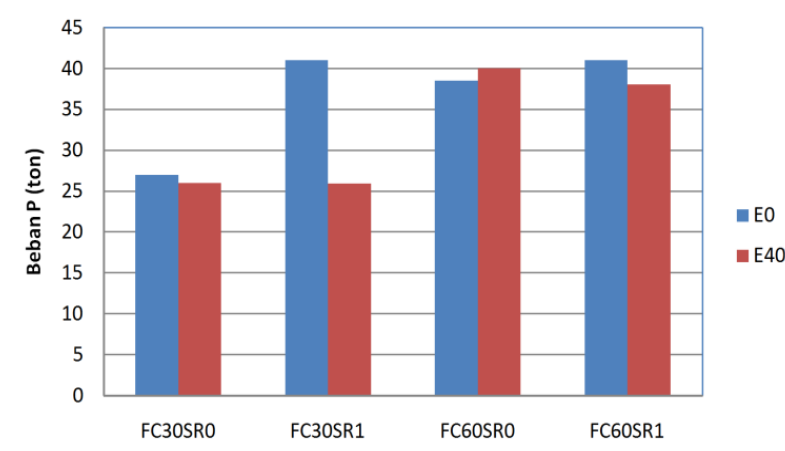

Gambar 21. Grafik kapasitas punching shear benda uji dengan eksentrisitas 0 dan eksentrisitas $40 \mathrm{~mm}$ pada berbagai kondisi 


\section{Pengaruh Penggunaan Tulangan Geser}

Beban maksimum $\mathrm{FC}_{30} \mathrm{E}_{0} \mathrm{SR}_{0}$ sebesar 27,00 ton sedangkan beban maksimum $\mathrm{FC}_{30} \mathrm{E}_{0} \mathrm{SR}_{1}$ lebih besar yaitu sebesar 41,06 ton (terjadi peningkatan sebesar 52,07 \%). Beban maksimum $\mathrm{FC}_{30} \mathrm{E}_{40} \mathrm{SR}_{0}$ sebesar 26,00 ton, sedangkan beban maksimum $\mathrm{FC}_{30} \mathrm{E}_{40} \mathrm{SR}_{1}$ hampir sama yaitu sebesar 25,97 ton (terjadi penurunan sebesar 0,12\%). Beban maksimum $\mathrm{FC}_{60} \mathrm{E}_{0} \mathrm{SR}_{0}$ sebesar 38,55 ton, sedangkan beban maksimum $\mathrm{FC}_{60} \mathrm{E}_{0} \mathrm{SR}_{1}$ lebih besar yaitu sebesar 41,07 ton (terjadi peningkatan sebesar 6,46\%). Beban maksimum $\mathrm{FC}_{60} \mathrm{E}_{40} \mathrm{SR}_{0}$ sebesar 40,04 ton, sedangkan beban maksimum $\mathrm{FC}_{60} \mathrm{E}_{40} \mathrm{SR}_{1}$ lebih kecil yaitu sebesar 38,07 ton (terjadi penurunan sebesar $4.92 \%$ ). Data di atas dapat dilihat pada Gambar 21.

Data pada grafik tersebut menunjukkan ada 2 dari 4 pengamatan benda uji yang beban maksimumnya lebih besar pada slab yang menggunakan tulangan geser yaitu pada kondisi beban sentris. Sedangkan 2 pengamatan benda uji lagi menunjukkan beban maksimumnya lebih besar pada slab yang tidak menggunakan tulangan geser yaitu pada kondisi beban eksentris.

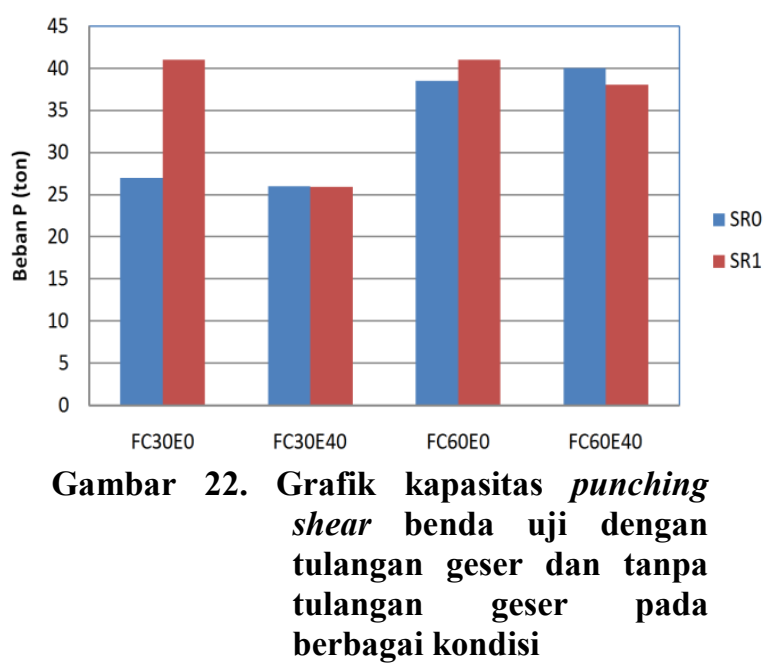

\section{KESIMPULAN DAN SARAN}

\section{Kesimpulan}

1. Mutu beton berpengaruh terhadap kapasitas punching shear. Hal ini ditunjukkan dengan adanya peningkatan beban maksimum yang sanggup ditahan oleh flat slab pada mutu beton yang lebih tinggi.

2. Eksentrisitas kolom memperkecil kapasitas punching shear. Hal ini dapat dilihat pada 3 pengamatan benda uji yang kapasitasnya turun.

3. Penggunaan tulangan geser tidak selalu memperbesar kapasitas punching shear. Dari 4 pengamatan benda uji terdapat 2 pengamatan mengalami kenaikan kapasitas sedangkan 2 pengamatan lagi mengalami penurunan kapasitas Penggunaan tulangan geser pada flat slab dapat memperbesar kapasitas punching shear pada kondisi beban sentris sedangkan penggunaan tulangan geser pada slab dengan 
kondisi beban eksentris justru memperkecil kapasitas punching shear.

4. Defleksi kolom yang terjadi pada benda uji dengan beban sentris lebih besar dari benda uji dengan beban eksentris. Hal ini disebabkan karena kapasitas punching shear pada kondisi beban sentris lebih besar dari kondisi pada beban eksentris.

\section{Saran}

1. Eksentrisitas yang diberikan agar lebih besar sehingga pengaruh yang ingin dilihat bisa tampak lebih nyata.

2. Tulangan geser yang dipasang agar lebih banyak atau lebih besar sehingga pengaruh yang ingin dilihat bisa tampak lebih nyata.

3. Ketebalan slab agar dibuat lebih besar dan bervariasi sehingga pengaruh yang ingin dilihat bisa tampak lebih nyata.

4. Penelitian dapat dilanjutkan dengan ketebalan slab sebagai variabel.

5. Membuat benda uji yang tahan terhadap pengaruh lentur tanpa pemasangan tulangan lentur sehingga pengaruh tulangan lentur pada punching shear bisa dieliminasi.

\section{DAFTAR PUSTAKA}

Albrecht, U 2002, Design of flat slabs for punching - European and North American practices, Cement \& Concrete Composites 24, 531-538.
Anonim 1, ACI 211.1-91 Standard Practice for Selecting Proportions for Normal, Heavyweight, and Mass Concrete, American Concrete Institute.

Anonim 2, ACI 318-2002 Building Code Requirements for Structural Concrete, American Concrete Institute.

Anonim 3, ASTM C33-99 Standard Specification for Concrete Aggregates, American Society for Testing and Materials.

Anonim 4, SNI 03-1974-1990 Metode Pengujian Kuat Tekan Beton, Departemen Pekerjaan Umum, Badan Penelitian dan Pengembangan, Jakarta.

Anonim 5, SNI 03-2493-1991 Metode Pembuatan dan Perawatan Benda Uji Beton di Laboratorium, Departemen Pekerjaan Umum, Badan Penelitian dan Pengembangan, Jakarta.

Anonim 6, SNI 03-2847-2002 Tata Cara Perhitungan Struktur Beton untuk Bangunan Gedung, Departemen Pemukiman dan Prasarana Wilayah, Badan Penelitian dan Pengembangan, Jakarta.

Anonim 7, SNI 07-2529-1991 Metode Pengujian Kuat Tarik Baja Beton, Departemen Pekerjaan Umum, Badan Penelitian dan Pengembangan, Jakarta. 
Jurnal Teknik Sipil Unaya

Anonim 8, SNI 03-6468-2000 Tata Cara Perencanaan Campuran Beton Berkekuatan Tinggi Dengan Semen Portland dan Abu Terbang, Departemen Pemukiman dan Prasarana Wilayah, Badan Penelitian dan Pengembangan, Jakarta.

Hallgren, Kinnunen \& Nylander 2002, Punching shear tests on column footings.

Krüger, G; Burdet, O \& Favre, R 1998, Punching tests on RC flat slabs with eccentric loading, Proceeding $2^{\text {nd }}$ Int. Ph.D. Symposium in Civil Engineering.

MacGregor, J.G 1997, Reinforced Concrete, John Wiley \& Sons, New York.

Ruiz, M.F \& Muttoni, A 2009, Applications of Critical Shear Crack Theory to Punching of Reinforced Concrete Slabs with Transverse Reinforcement, ACI Structural Journal, Title no. 106S46 